\title{
Optimization of EDM Parameters for Production of Biomedical Materials
}

\author{
Mukesh Kumar Rakesh \\ Department of ME \\ Sagar Institute of Research \& Technology(SIRT) \\ Bhopal (M.P), India \\ ermkrakesh@gmail.com
}

\author{
Dr. Syed Faisal Ahmed \\ Department of ME \\ Sagar Institute of Research \& Technology(SIRT) \\ Bhopal (M.P), India \\ faisalsyed08@gmail.com
}

\begin{abstract}
The finite element method (FEM) is used for simulating complex intricate shapes of industrial sheet forming operation. Effective physical parameters, as well as the numerical solution, influence the parameters of this phenomenon and its numerical prediction of results. In this study, to investigate the influence of different embossing patterns and embossing depths on the critical areas appearing during deep-drawn of a cylindrical cup. The numerical results are found from the literature survey to be in good agreement with the experimental results and accurate thinning distributions had been predict.
\end{abstract}

Keywords: FEM, EDM, Material removal rate, surface roughness.

\section{INTRODUCTION}

A biomedical devices are devices manufactured to replace a missing biological structure, to support a damaged biological structure or to improve an existing biological structure. Medical implants are artificial devices in contrast to transplantation, which involves transplanting biomedical tissue. The surface of the implants that come into contact with the body can be made with a biomedical material such as titanium, silicone or apatite, whichever is more functional [1]. In some cases the systems contain electronic components, eg. Artificial cardiac pacemakers and cochlear implants. Some implants are bioactive, such as subcutaneous drug delivery devices in the form of implantable pills or drug eluting stents. In recent years, more and more large medical companies and their suppliers have shifted the production of parts from conventional machining to spark erosion. This study examines the growth of EDM as a technique for manufacturing medical implants and other medical device components. In this modern era of digitalization of technology and global competitiveness, businesses and industries need to save time and money. You can only see this through the optimization of the process parameters. The EDM process suffers from a number of limitations such as: higher energy consumption, high initial investment costs and a large surface area. Additionally, it can only process conductive materials and is more expensive than traditional methods such as milling and turning. Therefore, careful selection of the different parameters and careful planning are recommended before starting the treatment process [2]. Selecting the correct machining parameters is critical to achieving optimal machining results. Many researchers and academics have attempted to optimize various manufacturing processes (conventional and unconventional) through traditional and non-traditional optimization methods, taking into account various process parameters in order to achieve optimal results. For EDM, MRR (material removal rate) and Ra (roughness parameter, mean roughness) are considered to be the most important parameters and the need to maximize MRR and minimize Ra has always been the goal of many researchers and industries. Real-world problems are complex because they are multidimensional, multimodal and encourage IT professionals to develop better and more effective problem-solving methods. Nature-inspired metaheuristic worked better than traditional approaches. So far, researchers have presented and experimented with various nature-inspired metaheuristic algorithms to solve various research problems.

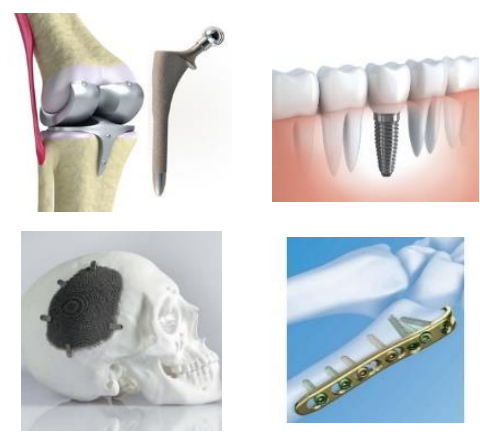

Fig. 1 Biomedical Devices 


\section{LITERATURE REVIEW}

Aharwal et al. [5] Optimization of machining parameters on the electric discharge machine (EDM) with $\mathrm{AlSiC}$ as the work piece and pure copper as the electrode. The machining parameters examined in this thesis are the material removal rate (MRR) and the surface roughness. The control parameters used are discharge voltage (v), discharge current (Ip), pulse charge factor (Tau), pulse activation time (ton). The Taguchi technique (L16b orthogonal matrix) was used for the experimental design and the genetic algorithm for optimization. Material removal rate analysis provides optimal values when current is high and voltage is low, while surface roughness is best when both are low.

Mohan et al [6] investigated the influence of the rotating tube electrode on the machining properties of Sic / 6025 aluminum composite materials. In his study, he found the positive effect of peak current on surface roughness (SR), rate of material removal (MRR) and tool wear rate (TWR). TWR, MRR and SR were greater when treated with positive versus negative polarity. The pulse duration was inversely proportional to TWR, MRR and SR. The speed and diameter of the electrode hole had a great influence on the material removal rate and the decrease in SR and TWR. The genetic algorithm was used to achieve an optimal stock removal rate, better surface quality and minimal tool wear.

Khan et al [7] evaluated tool wear along the tool length versus wear along its cross section. The wear of brass and copper tools increased with increasing current and voltage, but the wear along its cross section was greater than that along its length. As the current wear rate increases, this has also increased, demonstrating that with increasing current, both material removal and tool wear increase, but tool wear increases relatively more. The highest wear rate was found for steel when using brass as the tool electrode. A faster material removal rate was observed using a brass electrode on an aluminum part. When machining steel using a copper electrode, the material removal rate was low due to the low thermal conductivity of the workpiece.

Muttamara et al [8] compared the effect of creating conductive layers on alumina using graphite infiltrated with graphite, copper and copper according to the properties of EDM. When copper infiltrated graphite was used in the processing of $95 \%$ pure alumina, the material removal rate was much higher and the tool wear rate was lower than that of the graphite electrode and copper. The material removal rate was increased by $60 \%$ using a straight polarity graphite electrode, while the material removal rate was increased by $80 \%$ using linear polarity copper infiltrated graphite and under the same conditions. No copper elements were found on the conductive layers with graphite and copperinfiltrated graphite, while the results were examined by energy dispersive spectroscopy (EDS). With straight polarity copper infiltrated graphite, a surface roughness of $25 \mu \mathrm{m}$ was achieved.

\section{PRoposed Methodology}

The demand for biomedical implants is rapidly growing in order to improve the quality of human life. Such artificial components (implants) can be used for a short period of time, long-term, or even permanent in the biological tissue if not removed surgically [1]. Today, implants are used in many different parts of the body for a variety of applications such as orthopedics, pacemakers, cardiovascular stents, neural prostheses or drug delivery systems $[2,3]$. Biomedical components should generally have good corrosion resistance, adequate surface properties, sufficient mechanical strength, and biocompatibility with tissues and bones, which are naturally degraded and disappeared in tissues, as well as chemical stability and reliable safety [4]. In this case, metal alloys such as stainless steel, titanium and its alloys, cobaltchromium alloys, nickel-titanium shape memory alloys and magnesium alloys are the most preferred biomaterials. However, ceramics and polymers can also be used as implants. In order to modify the corrosion resistance, the surface and substrate qualities of machined magnesium alloys are generally improved by additional finishing processes such as electro-erosion (EDM).

EDM is one of the most advanced non-traditional operations that remove material from the part through evaporation, melting and erosion. During erosion, the electrode is held at a constant distance from the work piece. The electrode and the work piece form a circuit, while the electrode is treated as a cathode and the work piece is treated as an anode. Due to the presence of dielectric and current, a potential difference developed between the electrode and the work piece and generated a spark. Due to spark erosion, conductive parts of any hardness and complex shape can be processed very easily.

\section{A. Proposed Methodology}

\section{Flowchart of Work}

The optimized level of production of implant devices is considered to be potential and research efforts have already been made to develop it further. These methods generally pose technical problems based on a poor understanding of optimal material removal rate operation. Following steps are to tb followed for optimized material removal rate for implant production are: 
- $\quad$ Step 1: Choosing the appropriate material dataset.

- Step 2: Simulation model designing for EDM process.

- Step 3: Optimizing the material removal rate as well surface roughness of the material. This is performed on considering the optimal level of voltage, current, pulse on time as well pulse duty factor

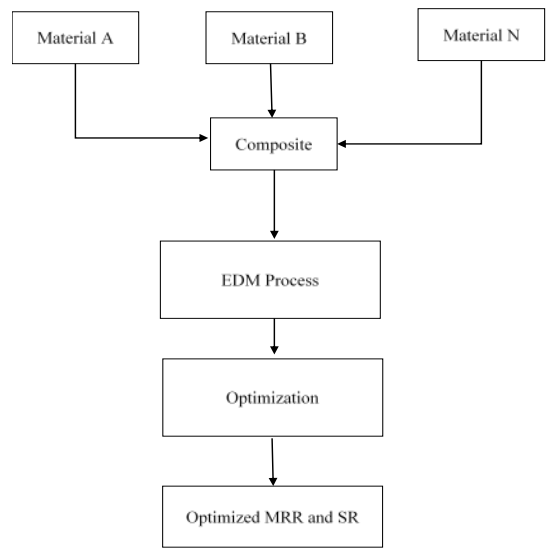

Fig. 2 Flow chart of Implant Production

\section{Material Selection}

The data is taken from [5]. In this paper, the work piece material used was aluminum silicon carbide composite in the form of a $55 \times 55 \times 22 \mathrm{~mm}^{3}$ block. The centrifugal casting method was used for the preparation of Al-SiC material. These properties and data were collected from research work.

\section{Machining}

The experimental study was carried out using dielectric fluid as EDM oil on Electric discharge Machine, (Table: 550x350 sq $\mathrm{mm}, \mathrm{X}: 300 \mathrm{~mm}$, Y: 200mm, Z: 250mm, MOFSET pulse generator). These machining process were collected from research work [5].

\section{Multi objective Parameter Optimization}

For these objectives, Multi Objective Optimization Algorithm (MOOA) is proposed. For a multi-objective optimization problem, the aim is to find a feature vector, $X=\left\{x_{1}, x_{2} \ldots x_{n}\right\}$ which will satisfy the constraints (eqn 7).

$$
\begin{array}{ll}
\left\{f_{1}(x) \geq 0,\right. & i=1,2,3, \ldots \ldots, P\} \\
\left\{f_{2}(x) \geq 0,\right. & j=1,2,3, \ldots \ldots, Q\}
\end{array}
$$

and will minimize the vector function (eqn 8 ).

$$
\begin{gathered}
F(X)=\left\{f_{1}(x), f_{2}(x), \ldots \ldots f_{m}(x)\right\} \\
X=\left\{x_{1}, x_{2} \ldots x_{n}\right\} \in \Omega
\end{gathered}
$$

Where $\mathrm{X}=$ feature vector, $f_{1}(x)$ and $f_{2}(x)=$ Objective functions having maximum limits of $\mathrm{P}$ and $\mathrm{Q}$ respectively. the set $\Omega$ denotes the feasible region, $\mathrm{m}=$ number of objective functions to be minimized.

The measured data collected from simulated mathematical model for the optimizing MRR and SR. The result obtained from optimization which is implemented in MATLAB. In order to obtain the best solution for maximum MRR output and minimum SR output.

Maximize MRR and Minimize SR [5]:

$$
\begin{gathered}
\text { MRR }=19.9+5.305 \mathrm{Ip}-0.464 \mathrm{~V}+0.0394 \mathrm{Ton}+ \\
0.886 \mathrm{Tau} \\
\mathrm{SR}=2.926+0.2303 \mathrm{Ip}+0.0235 \mathrm{~V}+0.004323 \mathrm{Ton} \\
-0.0222 \mathrm{Tau}
\end{gathered}
$$

Where,

$\mathrm{I}_{\mathrm{P}}=$ Peak Current

$\mathrm{V}=$ Gap Voltage

$\mathrm{T}_{\mathrm{on}}=$ Pulse on Time

$\mathrm{Tau}=$ Duty Factor

Algorithm: Proposed Multi-objective Optimization

Start

Select input parameters: population size $(\mathrm{P})$, no. of population, maximum iteration $\left(i_{\max }\right)$, local and global constant variables, objective functions, lower and upper bounds of objective functions.

Generate population of size $\left(\mathrm{x}=\mathrm{x}_{1}, \mathrm{x}_{2}, \mathrm{x}_{3} \ldots \ldots \mathrm{x}_{\mathrm{dim}}\right)$

For $\mathrm{i}=1$ to $\mathrm{i}_{\max }$

For $\mathrm{j}=1$ to $\mathrm{P}$

Fitness (population);

If fitness_val $<$ switch probability

Update the position of population;

End 
Fitness (population); (population)

If Updated Fitness (population) < Best Fitness

Return Best Fitness (population) and update position;

\section{End}

End

End

Output best population found

End

The flow-chart of proposed swarm multi-objective optimized dimension methodology is illustrated in figure 3 .

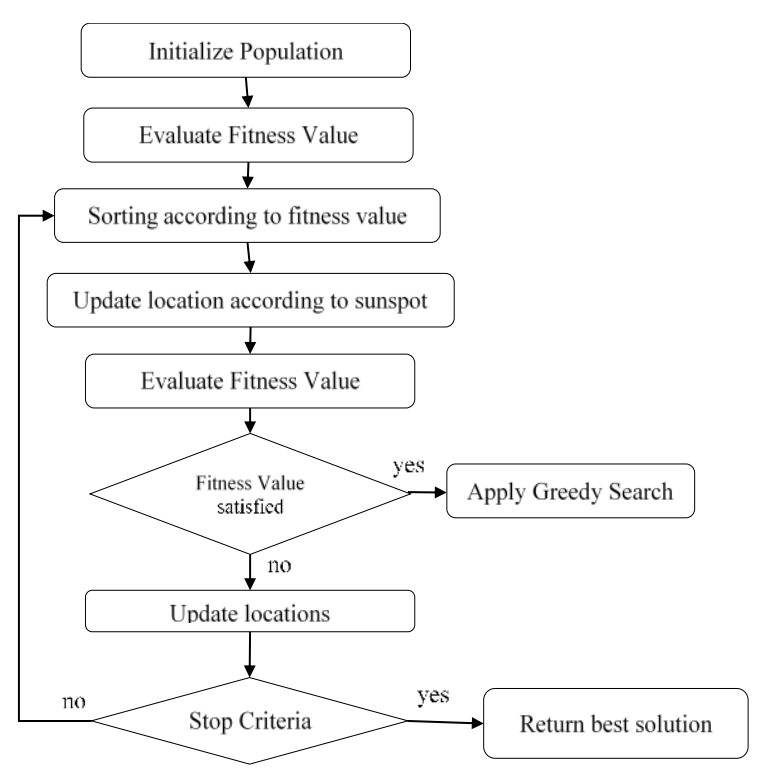

Fig. 3 Flowchart of Multi-objective Swarm Optimization

\section{RESUlTS AND DisCUSSION}

For implementation of proposed methodology, MATLAB platform is used to implement and to analysis of result. This section also discusses about the performance parameters that are used to analyze the performance of the system. Material removal rate and SR optimization along with convergence curve are used as a performance parameter.

\section{A. Performance Parameters}

In this research work, the material properties and experimental results are taken from [5] which used a metal matrix composite aluminium silicon carbide can be made by combining Aluminium and Silicon Carbide by using either powder metallurgy method or centrifugal casting method. The properties of the material depend on the proportion of the components. The presence of silicon makes the material cheaper and harder. As the silicon content in the composite increases, the product becomes harder, but then the machinability of the product becomes more difficult. In order to know the silicon carbide content so that you also have good workmanship, it is important to examine the workability by testing different combinations of components. Each experiment runs with a certain set of input parameters and a certain depth of processing for all combinations of experiments. The level of the input parameters is shown in Table 1.

Table 1: Input Parameter Values

\begin{tabular}{|c|c|c|c|c|c|}
\hline $\begin{array}{c}\text { EDM } \\
\text { Factors }\end{array}$ & Units & Level_1 & Level_2 & Level_3 & Level_4 \\
\hline $\begin{array}{c}\text { PEAK } \\
\text { CURRENT }\end{array}$ & Ampere & 5 & 10 & 12 & 15 \\
\hline $\begin{array}{c}\text { GAP } \\
\text { VOLTAGE }\end{array}$ & Volts & 40 & 45 & 50 & 55 \\
\hline $\begin{array}{c}\text { PULSE ON } \\
\text { TIME }\end{array}$ & $\mu$ Second & 100 & 150 & 200 & 250 \\
\hline \begin{tabular}{c} 
Duty Factor \\
\hline
\end{tabular} & - & 20 & 25 & 27 & 30 \\
\hline
\end{tabular}

In this work two responses namely Material Removal Rate (MRR) and Surface Roughness (SR) are taken into consideration.

Material Removal Rate (MRR)

MRR is calculated by difference of work specimen's pre machining weight and post machining weight, So MRR is calculated by equation:

$$
\operatorname{MRR}=\left(\frac{W_{i}-W_{f}}{t \times \rho}\right) m^{3} / \mathrm{min}
$$

Where,

$W_{i}=$ Pre machining weight of specimen $(\mathrm{kg})$.

$W_{f}=$ Post machining weight of specimen $(\mathrm{kg}$.$) .$

$\mathrm{t}=$ Machining Time(min.). 
$\rho=$ Density of En-24 $\left(7.84 \times 10^{-6} \mathrm{~kg} / \mathrm{mm}^{3}\right)$.

Material removal rate is directly proportional to pulse-on time, discharge current and supply voltage and inversely proportional to spark-off time.

\section{Surface Roughness (SR)}

The quality of surface after machining is evaluated with surface quality measure such as surface roughness.

\section{B. Result Analysis}

A prediction model for surface roughness and MRR are established by taking surface roughness/MRR as a dependent variables and input variables (pulse-on time, supply voltage, current and duty factor) as independent variables. Linear regression equations are established between them using MATLAB 2018 software, and the statistical tests (F-test and ttests) are carried out to test the significance levels.

In linear regression analysis, the general form of equation is as shown in below in equation (6):

$$
R a=a_{1} x_{1}+a_{2} x_{2}+a_{3} x_{3}+\ldots \ldots \ldots \ldots+a_{n} x_{n}+k
$$

In both the above case, $\mathrm{a}_{1}, \mathrm{a}_{2}, \mathrm{a}_{3}$, and $\mathrm{a}_{\mathrm{n}}$ are parameters and $\mathrm{x}_{1}$, $\mathrm{x}_{2}, \mathrm{x}_{3}$, and $\mathrm{x}_{\mathrm{n}}$ represent the selected input variables, and ' $\mathrm{k}$ ' is a constant.

This Multi-objective swarm optimization (MO-SO) is used to optimize process parameter for maximize MRR and minimize SR simultaneously. While, SO is used to optimize process parameter for minimize single function only. Hence for maximizing MRR, inverse of its value is taken.

when the iteration stage is finished up, the algorithm yields the best search space with best fitness. Multi-objective swarm optimization for MRR and SR is shown in below section. By changing weightage for MRR and SR different solutions can be found. For optimization of MRR and SR is performed with different iteration values and their graphs are shown below.

The experimental data has been shown in Table-2 [5].

\begin{tabular}{|c|c|c|c|c|c|c|}
\hline $\begin{array}{l}\text { Exp. } \\
\text { No. }\end{array}$ & Ip & V & Ton & Tau & MRR & SR \\
\hline 1 & 5 & 40 & 100 & 20 & 44.16 & 4.8 \\
\hline 2 & 5 & 45 & 150 & 25 & 58.41 & 5.27 \\
\hline 3 & 5 & 50 & 200 & 27 & 54.37 & 5.4 \\
\hline 4 & 5 & 55 & 300 & 30 & 60.96 & 5.8 \\
\hline 5 & 10 & 40 & 150 & 27 & 81.97 & 6.1 \\
\hline 6 & 10 & 45 & 100 & 30 & 88.77 & 6.3 \\
\hline 7 & 10 & 50 & 300 & 20 & 77.97 & 7.4 \\
\hline 8 & 10 & 55 & 200 & 25 & 76.77 & 7 \\
\hline 9 & 12 & 40 & 200 & 30 & 96.96 & 7.2 \\
\hline 10 & 12 & 45 & 300 & 27 & 93.56 & 7.6 \\
\hline 11 & 12 & 50 & 100 & 25 & 87.47 & 6.9 \\
\hline 12 & 12 & 55 & 150 & 20 & 81.97 & 7.4 \\
\hline 13 & 15 & 40 & 300 & 25 & 118.55 & 7.9 \\
\hline 14 & 15 & 45 & 200 & 20 & 108.96 & 7.7 \\
\hline 15 & 15 & 50 & 150 & 30 & 105.96 & 7.3 \\
\hline 16 & 15 & 55 & 100 & 27 & 98.96 & 7.3 \\
\hline
\end{tabular}

The regression equations obtained from linear regression analysis using MATLAB 18, are given below [5]:

$$
\begin{gathered}
\text { MRR = 19.9+5.305 Ip }-0.464 \mathrm{~V}+0.0394 \text { Ton }+ \\
0.886 \text { Tau } \\
\mathrm{SR}=2.926+0.2303 \mathrm{Ip}+0.0235 \mathrm{~V}+0.004323 \text { Ton }- \\
0.0222 \mathrm{Tau}
\end{gathered}
$$

\begin{tabular}{|c|c|c|c|c|c|}
\hline \multicolumn{4}{|c|}{ Optimal Parameters } & \multirow[b]{2}{*}{ MRR } & \multirow[b]{2}{*}{ SR } \\
\hline $\begin{array}{c}\text { Input } \\
\text { Current }\end{array}$ & Voltage & $\begin{array}{c}\text { Pulse on } \\
\text { Time }\end{array}$ & $\begin{array}{l}\text { Pulse Duty } \\
\text { Factor }\end{array}$ & & \\
\hline 11.36 & 40 & 100 & 20 & 85.456 & 5.6 \\
\hline 5 & 48.16 & 100 & 20 & 48.732 & 4.105 \\
\hline 5 & 40 & 144.46 & 20 & 48.732 & 4.105 \\
\hline 5 & 40 & 100 & 27.02 & 48.732 & 4.105 \\
\hline 10.95 & 46.38 & 149.79 & 28.95 & 86.65 & 5.65 \\
\hline
\end{tabular}

\section{MRR and SR Optimization Result}



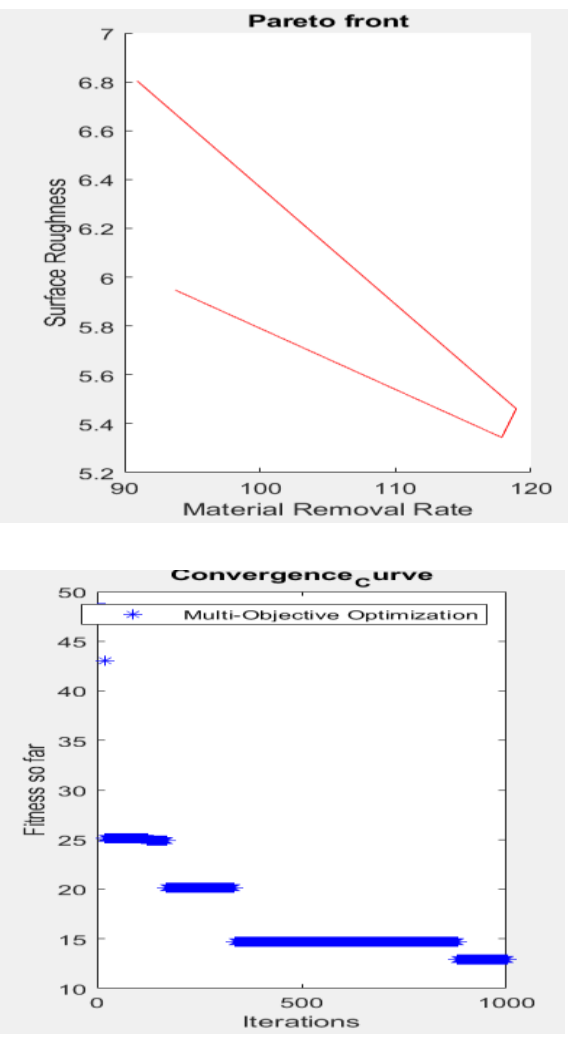

Fig. 3 Impact of Input Current on MRR and SR

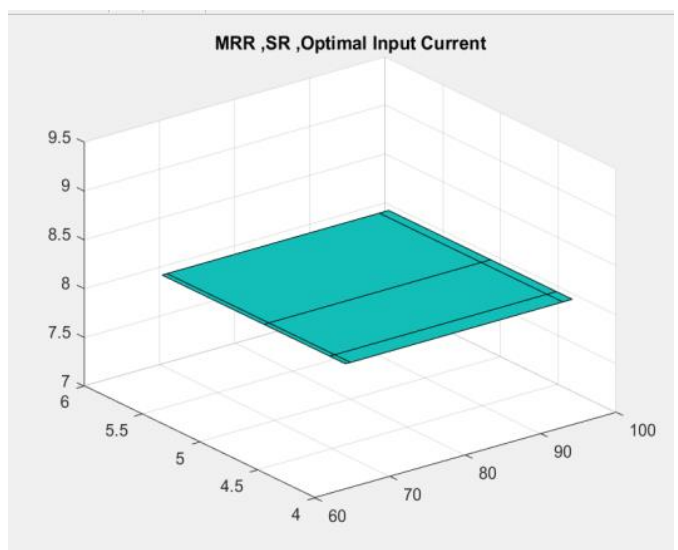

Fig. 4 Best Optimal Solution of MRR and SR on Input Current

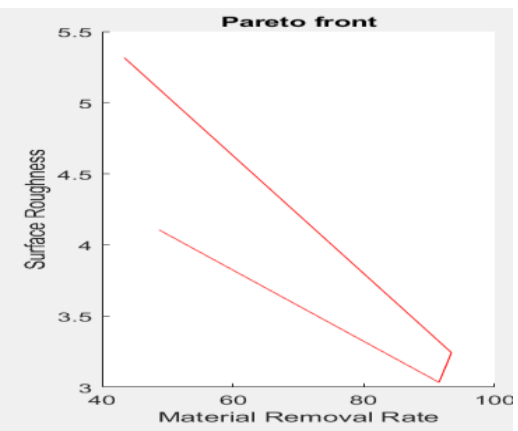

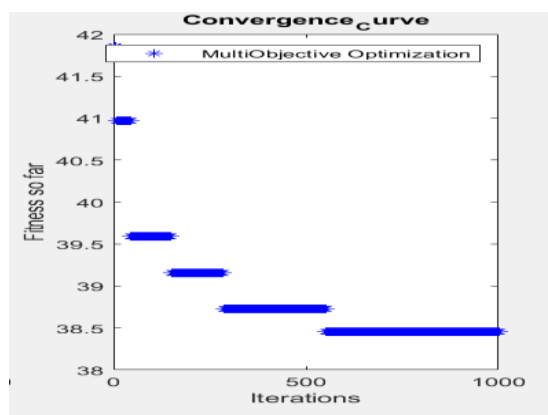

Fig. 5 Impact of Voltage on MRR and SR

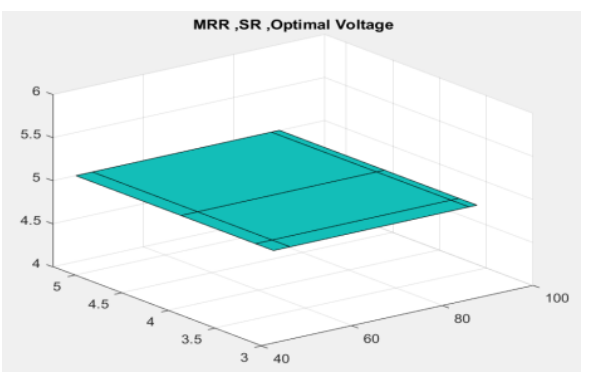

Fig. 6 Best Optimal Solution of MRR and SR on Voltage

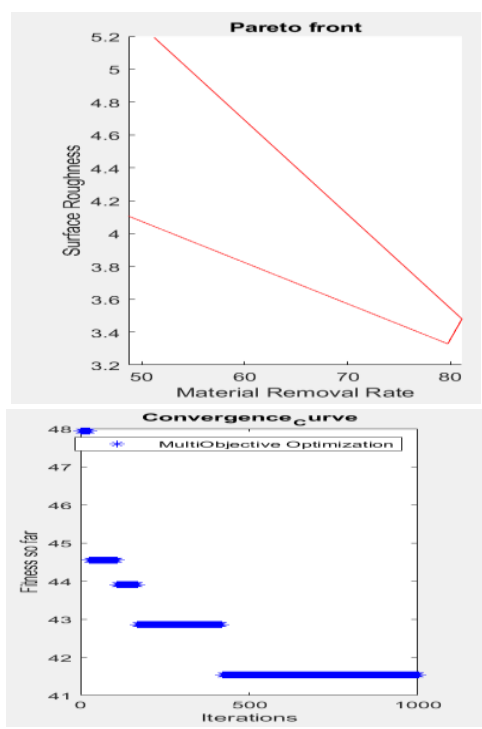

Fig. 7 Impact of Pulse on Time on MRR and SR 


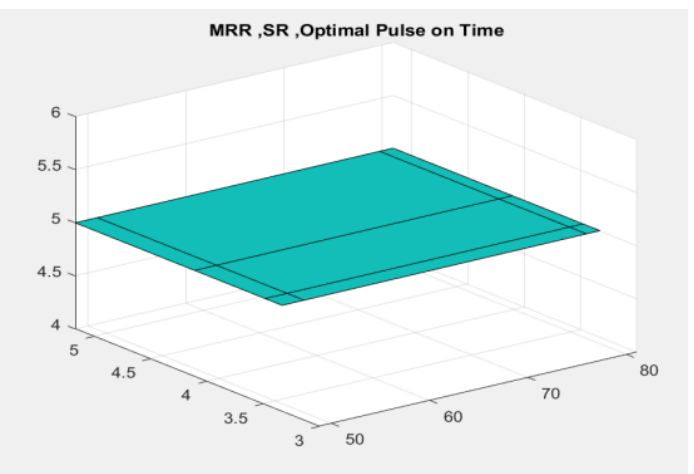

Fig. 8 Best Optimal Solution of MRR and SR on Pulse On Time

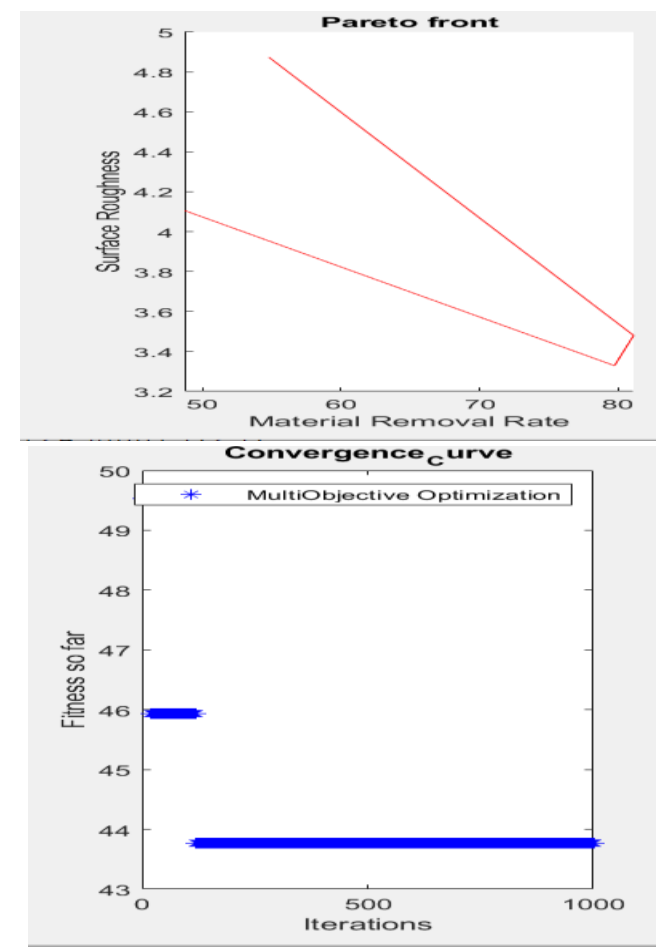

Fig. 9 Impact of Pulse Duty Factor on MRR and SR

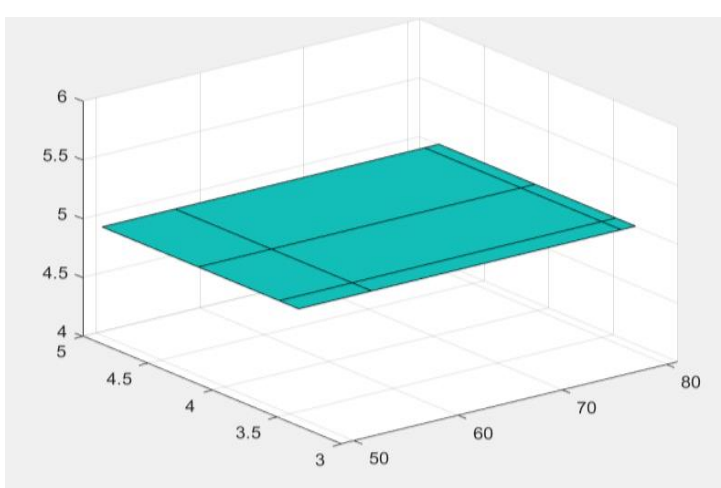

Fig. 10 Best Optimal Solution of MRR and SR on Pulse Duty Factor
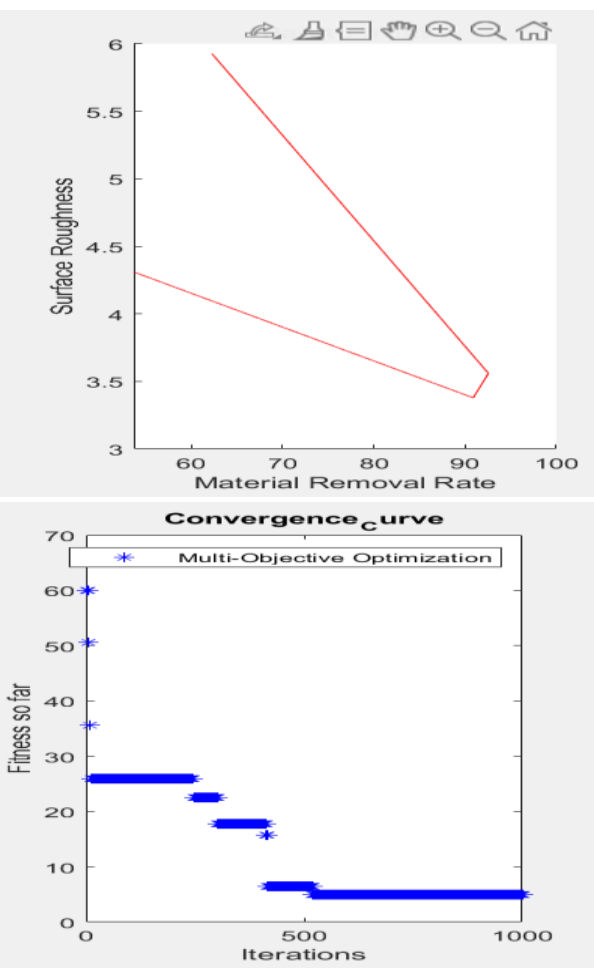

Fig. 11 Impact of All Parameters on MRR and SR

\section{Error Evaluation}

\begin{tabular}{|c|c|c|c|c|c|c|}
\hline \multicolumn{2}{|c|}{ Optimal Parameters } & \multirow{2}{*}{$\begin{array}{c}\text { MRR } \\
\text { Error }\end{array}$} & $\begin{array}{c}\text { SR } \\
\text { Error }\end{array}$ & $\begin{array}{c}\text { Mean } \\
\text { Error }\end{array}$ \\
$\begin{array}{c}\text { Input } \\
\text { current }\end{array}$ & Voltage & $\begin{array}{c}\text { Pulse on } \\
\text { Time }\end{array}$ & $\begin{array}{c}\text { pulse } \\
\text { duty } \\
\text { factor }\end{array}$ & & & \\
\hline 11.36 & 40 & 100 & 20 & 0.65 & 1.34 & 0.99 \\
\hline 5 & 48.16 & 100 & 20 & 3.671 & 3.89 & 3.78 \\
\hline 5 & 40 & 144.46 & 20 & 3.671 & 3.89 & 3.78 \\
\hline 5 & 40 & 100 & 27.02 & 3.671 & 3.89 & 3.78 \\
\hline 10.95 & 46.38 & 149.79 & 28.95 & 1.095 & 2.04 & 1.57 \\
\hline
\end{tabular}

\section{E. Validation of Results}

For validation purposes, different separate experiments were conducted, and the data were recorded. The value of MRR is computed using prediction model and measured and both are compared. It is observed that the maximum percentage of error was 7\% for MRR in [31]. Whereas in this research methodology, 
error for MRR was $4 \%$. So, it can be concluded that there is improvement of $3 \%$ of this research work as compared with existing work.

\section{CONCLUSION AND FUtURE WORK}

The investigation on conventional and advanced machining of biocompatible materials has demonstrated the potential to produce a variety of biocompatible material specifications which can be used as implants. These machining processes can improve the quality of machined biocompatible materials and at the end produce implants of complex shape from metals, polymers, ceramics, and composites. The various machining techniques have an effect on the physical properties of the implants which may have a significant influence on the biocompatibility. From this study, it was observed that MRR is significantly affected by pulse time. Review of the literature showed that researchers used experimental designs and optimization methods when machining various part materials. Very few researchers have attempted to determine the relationship between input parameters (gap current, gap voltage, on time and off time) and EDM performance measurements during implant material processing. In this research work, a multi-objective optimization of reactions such as material removal rate and surface roughness was performed using corbel optimization methods. The following conclusions are drawn from the analysis of the results:

- Following conclusion are derived from result analysis:

- These optimal values of input current, voltage, pulse on time and pulse duty factor was observed to be approx. 11A, 46V, $150 \mu \mathrm{s}, 29 \mathrm{~min}$ respectively.

- Optimal response parameters such as MRR and SR was observed to be 86 and 5.5 respectively.

- The most influencing factor for better surface finish is input current.

- MRR error was observed to be approx. $4 \%$ whereas SR is also $4 \%$ approx.

- There is improvement of $3 \%$ as compared to existing work.

- Optimization of EDM factors and parameters can improve the performance as well as reduces the environmental impact and production cost.

- The multi-objective optimization during EDM machining of materials under different scenarios can leads to the direction of manufacturing more biocompatible devices.

Further work in this area can be done in the area of analysis of the data by considering other multi objective optimization algorithms and optimization of following parameters:
- Material Removal Rate and Surface roughness

- Corrosion rate

- Degradation rate

- Tool Wear rate

\section{REFERENCES}

[1] Mitsuishi M, Cao J, Bartolo P, Friedrich D, Shih AJ, Rajurkar K, Sugita N, Harada K. Biomanufacturing. CIRP Annual Manufacturing Technology. 2013;62;585-606.

[2] Khan W, Muntimadugu E, Jaffe M, Domb AJ. Implantable medical devices. Focal controlled drug delivery: Springer. 2014; 33-59.

[3] Bartolo P, Kruth J-P, Silva J, Levy G, Malshe A, Rajurkar K, Mitsuishi M, Ciurana J, Leu M. Biomedical production of implants by additive electrochemical and physical processes. CIRP Ann Manuf Technol. 2012; 61; 635-655.

[4] Kumar N, Arora NC, Datta B. Bearing surfaces in hip replacement evolution and likely future. Med J Armed Forces India. 2014; 70;371-376.

[5] Aharwal K R, Sitaramb and CM Krishna. Optimization of Material Removal Rate and Surface Roughness in EDM Machining of Metal Matrix Composite using Genetic Algorithm. International Conference of Materials Processing and Characterization. Materials Today Proceeding. (2018), 5391-5397.

[6] Mohan, B., Rajadurai, A., Satyanarayana K. G., -Electric discharge machining of $\mathrm{Al}-\mathrm{SiC}$ metal matrix composites using rotary tube electrodell, Journal of Materials Processing Technology. 153-154 (10): 978- 985, 2004.

[7] A.A. Khan,"Electrode Wear And Material Removal Rate During EDM Of Aluminum and Mild Steel Using Copper And Brass Electrodes". International Journal of Advanced Manufacturing Technology, vol. 39, p. 482-487, 2008.

[8] A. Muttamara, Y. Fukuzawa, N. Mohri and T. Tani, Effect of electrode material on electric discharge machining of alumina. J. Mater. Process. Technol. 115 (2009) 344-358. 